\title{
Determinants of poorly controlled asthma among asthmatic patients in Jimma University Medical Center, Southwest Ethiopia: a case control study
}

\author{
Ameha Zewudie ${ }^{1^{*}}\left(\mathbb{D}\right.$, Tadesse Nigussie $^{2}$, Yitagesu Mamo $^{1}$ and Kabaye Kumela ${ }^{3}$
}

\begin{abstract}
Objective: The aim of this study was to assess determinants of poorly controlled asthma among asthmatic patients on follow up at Jimma University Medical Center, Southwest Ethiopia. A facility based case control study involving chart review and patient interview was conducted from April 01/2017 to May 30/2017. Consecutive sampling method was used to select 121 cases and 121 controls. Descriptive statistics were used to present socio demographic data and drug prescription pattern while logistic regression was used to identify predictors of poorly controlled asthma.

Results: From a total of 242 studied asthmatic patients, $52.9 \%$ of controls and $44.6 \%$ of cases were males. Poor knowledge about asthma [Adjusted odd ratio(AOR) $=7.30 ; 95 \%$ confidence interval $(\mathrm{Cl}) 1.72-30 ; \mathrm{P}=0.007$ ], negative attitude about asthma $[A O R=5.10 ; 95 \% \mathrm{Cl} 1.40-18.7 ; \mathrm{P}=0.014]$, moderate asthma $[\mathrm{AOR}=13.47 ; 95 \% \mathrm{Cl} 2.69-47.23$; $\mathrm{P}=0.002]$ and non-adherence to inhaled corticosteroid (ICS) $[\mathrm{AOR}=8.52 \% ; 95 \% \mathrm{Cl} 2.41-13.45 ; \mathrm{P}=0.001$ ] were determinants of poorly controlled asthma.
\end{abstract}

Keywords: Asthma, Poorly controlled asthma, Ethiopia

\section{Introduction}

Worldwide, approximately 180,000 deaths annually are attributable to asthma. There has been a sharp increase in the global prevalence, morbidity, mortality and economic burden associated with asthma over the last 40 years. Asthma can place considerable limitations on the physical, emotional, social and professional lives of sufferers. These may be greater when symptoms are not adequately controlled [1].

Economic burden of asthma is also considerable. In the United States, the total direct medical and indirect economic costs of asthma were approximately $\$ 12$ billion in 1994 [2]. In Europe, the total cost of asthma currently covers at approximately $\$ 21.65$ billion per year [1]. In

*Correspondence: amehazewudie@gmail.com

1 Department of Pharmacy, College of Health Science, MizanTepi University, Mizan-Aman, Ethiopia

Full list of author information is available at the end of the article developing countries, annual asthma cost was estimated at $\$ 20$ billion [3].

The control of asthma symptom is a realistic goal. Studies have shown that this can be achieved in most asthmatic patients which lead to a higher quality of life. In spite of this, the control of asthma is generally poor. The Asthma Insights and reality in Europe study reported persistence day time symptoms of up to $46 \%$ among asthmatic patients under treatment [4]. Ethiopia is not an exception. Studies done in Jimma University Medical Center (JUMC) reported that greater than half of asthmatic patients had poorly controlled asthma $[5,6]$.

To solve this problem, World Health Organization (WHO) developed guideline for chronic diseases management including asthma and the development of questionnaire tools to measure asthma control. One such tool is the asthma control test (ACT) which is based on 5 items survey that assess interference with activity, shortness of breath, nocturnal symptom, rescue medication use and self rating of asthma symptoms [7]. 
Regardless of these interventions, asthma is poorly controlled all over the world, particularly in developing countries. Hence, this study aimed at identifying predictors of poorly controlled asthma among asthmatic patients on follow up at JUMC.

\section{Main text \\ Methods}

The study was conducted at JUMC, which is found in Jimma town, Southwest Ethiopia. Hospital based unmatched case-control study was conducted from April 01/2017 to May 30, 2017 G.C. The source population was all adult asthmatic patients who were on follow up at JUMC. The study population consists of asthmatic patients attending chest clinic during the study period and fulfill inclusion criteria. Patients who had at least 3 months consecutive follow up and age 18 years or older were included. Patients with lung cancer, congestive heart failure, chronic obstructive pulmonary disease, pulmonary hypertension and interstitial lung disease were excluded due to similarities in symptoms with asthma which make the assessment of asthma severity more difficult. Mentally unstable or critically ill patients were also excluded.

Controls were patients with well controlled asthma (average short acting B-agonist (SABA) consumption $\leq 2$ days per week for three consecutive months), no night awaking for three consecutive months and no emergency visits or oral courses of steroids during the past 6 months, whereas patients with poorly controlled asthma (average SABA consumption $>2$ days per week for three consecutive months) or if $\geq 1$-night awakenins per week for three consecutive months, or any emergency visits or oral courses of steroids during the past 6 months were considered as cases $[4,6,8]$.

Asthma severity was assessed by Global Initiative for Asthma (GINA) asthma symptom control assessment tool [8], which has been correlated to other standardized asthma severity score [1]. Adherences to controllers were assessed by using Morisky 8 item medication adherence questionnaires. Accordingly, high adherence is considered if the patient score 0 , medium adherence if score is 1-2 and low adherence if score is $>2$. Medium adherence and low adherence were considered to be non-adherent $[9,10]$. Patients knowledge about Asthma was assessed based on 20 asthma knowledge questions. Participants who achieved knowledge score $\leq 8$ were considered as having poor knowledge, 9-12 as average knowledge and $\geq 13$ as good knowledge. Average knowledge and good knowledge was considered as good knowledge [11, 12]. Attitude towards Asthma was evaluated with five-point Likert scale ranging from strongly disagrees to strongly agree. Total score of attitude domain ranged from 5 to 25. Patient's attitudes were categorized into two groups, positive attitude if the score was $\geq 15$ and negative attitudes if the score was $<15$ [12].

Epi info version 7 was used to calculate sample size by two population proportion with the assumption of $95 \%$ CI $80 \%$ power, and 1:1 case to control ratio. OR and proportion of different determinant variables of asthma control among control was taken from recent study done at JUMC [5, 6]. After calculation, smoking gave the largest sample size which is 242 . Consecutive sampling method was applied until the required sample size of both of the groups achieved.

Semi-structured questionnaires and check lists were used to collect data from the patients and their medical record respectively. The data entry was made by using Epidata manager 4.0.2.101 and statistical analysis was done by statistical Package for Social Science (SPSS) version 21. Descriptive statistics such as mean, median and standard deviations (SD) was used to summarize the results. All independent variables which have $\mathrm{P}$ value of less than 0.25 on binary logistic regression were selected as candidate for multivariable regression analysis. Then, multivariable logistic regression using back ward selection method was done to identify predictors of poorly controlled asthma at $P$ value $<0.05$

\section{Results}

\section{Socio demographic characteristics of the study participants}

One hundred twenty-one controls and 121 cases were included in the study. Of these, $112(92.6 \%)$ of the controls and $35(28.9 \%)$ of the cases had good knowledge about asthma. Eighty-nine (73.6\%) of the controls and 53 $(43.8 \%)$ of the cases had positive attitude towards asthma. Eighty-six (84.4\%) of controls and 13 (19.1) of cases were non adherent to ICS (Table 1).

\section{Diseases related factors}

According to the classification by GINA, 58 (47.9\%) of the cases and $39(32.2 \%)$ of the controls had moderate persistent asthma while $58(47.9 \%)$ of the cases and $9(7.4 \%)$ of the controls had severe persistent asthma (Table 2).

\section{Predictors of poorly controlled asthma}

Poor knowledge towards asthma, negative attitude towards asthma, moderate and severe asthma and nonadherence to ICS were independent predictors of poorly controlled asthma (Table 3).

\section{Discussion}

The present study showed that patients who had moderate and severe persistent asthma were found to be 13 and 20 times more likely to have uncontrolled asthma respectively. This finding is comparable with the study 
Table 1 Patient characteristics of the Asthmatic patients on follow up at Jimma University Medical Center, Southwest Ethiopia, 2017

\begin{tabular}{|c|c|c|c|c|}
\hline \multirow[t]{2}{*}{ Variables } & \multicolumn{2}{|l|}{ Control } & \multicolumn{2}{|l|}{ Case } \\
\hline & Frequency & $\%$ & Frequency & $\%$ \\
\hline \multicolumn{5}{|l|}{ Sex } \\
\hline Male & 64 & 52.9 & 54 & 44.6 \\
\hline Female & 57 & 47.1 & 67 & 55.4 \\
\hline \multicolumn{5}{|c|}{ Age of the respondent (years) } \\
\hline $18-34$ & 40 & 33.1 & 16 & 13.2 \\
\hline $35-54$ & 52 & 43.0 & 34 & 28.1 \\
\hline$>55$ & 29 & 24.0 & 71 & 58.7 \\
\hline \multicolumn{5}{|l|}{ Residence } \\
\hline Urban & 72 & 59.5 & 42 & 34.7 \\
\hline Rural & 49 & 40.5 & 79 & 65.3 \\
\hline \multicolumn{5}{|l|}{ Marital status } \\
\hline Single & 12 & 9.9 & 8 & 6.6 \\
\hline Married & 97 & 80.2 & 83 & 68.6 \\
\hline Divorced & 4 & 3.3 & 9 & 7.4 \\
\hline Widowed & 8 & 6.6 & 21 & 17.4 \\
\hline \multicolumn{5}{|l|}{ Educational status } \\
\hline Higher & 22 & 18.2 & 11 & 9.1 \\
\hline Secondary & 19 & 15.7 & 10 & 8.3 \\
\hline Primary & 37 & 30.6 & 26 & 21.5 \\
\hline Illiterate & 43 & 35.5 & 74 & 61.2 \\
\hline \multicolumn{5}{|l|}{ Occupational status } \\
\hline Government employee & 47 & 39.2 & 20 & 16.5 \\
\hline Merchant & 12 & 10 & 8 & 6.6 \\
\hline Housewife & 8 & 6.7 & 14 & 11.6 \\
\hline Farmer & 38 & 31.7 & 47 & 38.8 \\
\hline Retired & 6 & 5.0 & 25 & 20.7 \\
\hline Others & 10 & 8.2 & 7 & 5.8 \\
\hline \multicolumn{5}{|l|}{ Monthly income } \\
\hline$\leq 1200$ & 43 & 35.5 & 88 & 72.7 \\
\hline $1201-2499$ & 25 & 20.7 & 15 & 12.4 \\
\hline$\geq 2500$ & 53 & 43.8 & 18 & 14.9 \\
\hline \multicolumn{5}{|l|}{ Smoking status } \\
\hline Never & 108 & 89.3 & 68 & 56.2 \\
\hline Previously & 9 & 7.4 & 37 & 30.6 \\
\hline Current & 4 & 3.3 & 18 & 13.2 \\
\hline \multicolumn{5}{|l|}{ Residence } \\
\hline \multicolumn{5}{|l|}{ Urban } \\
\hline \multicolumn{5}{|l|}{ Rural } \\
\hline \multicolumn{5}{|l|}{ Chat chewing } \\
\hline Yes & 24 & 19.8 & 28 & 23.1 \\
\hline No & 97 & 80.2 & 93 & 76.9 \\
\hline \multicolumn{5}{|l|}{ Drinking alcohol } \\
\hline Yes & 116 & 95.9 & 105 & 86.8 \\
\hline No & 5 & 4.1 & 16 & 13.2 \\
\hline \multicolumn{5}{|l|}{ Visiting the doctor } \\
\hline Scheduled & 109 & 90.1 & 95 & 84.3 \\
\hline
\end{tabular}

Table 1 (continued)

\begin{tabular}{|c|c|c|c|c|}
\hline \multirow[t]{2}{*}{ Variables } & \multicolumn{2}{|l|}{ Control } & \multicolumn{2}{|l|}{ Case } \\
\hline & Frequency & $\%$ & Frequency & $\%$ \\
\hline Unscheduled & 12 & 9.9 & 26 & 15.7 \\
\hline \multicolumn{5}{|c|}{ Knowledge about asthma } \\
\hline Good & 112 & 92.6 & 35 & 28.9 \\
\hline Poor & 9 & 7.4 & 86 & 71.5 \\
\hline \multicolumn{5}{|c|}{ Attitude about asthma } \\
\hline Positive attitude & 89 & 73.6 & 53 & 43.8 \\
\hline Negative attitude & 32 & 26.4 & 68 & 56.2 \\
\hline \multicolumn{5}{|l|}{ ICS } \\
\hline Yes & 90 & 74.4 & 68 & 56.2 \\
\hline No & 31 & 25.6 & 55 & 43.8 \\
\hline \multicolumn{5}{|c|}{ Level of adherence to ICS } \\
\hline Adherent & 76 & 84.4 & 13 & 19.1 \\
\hline Non adherent & 14 & 15.6 & 55 & 80.9 \\
\hline
\end{tabular}

Others: unemployed, private workers but not merchant, student

done in JUMC which reported that poorly controlled asthma were about 6 times and 32 times more likely among patients with moderate and severe asthma respectively [6]. Similarly, study conducted in Brazil revealed that patient with persistent severe asthma were 5 times more likely to have uncontrolled asthma $(\mathrm{OR}=5.33$, $\mathrm{P}<0.0001$ ) [13]. Another study done in Saud Arabia also demonstrated that severity of asthma significantly affects asthma control [14].

The finding of this study demonstrated patients who had poor knowledge about asthma were about 7 times increased odds of poorly controlled asthma. This finding is in line with other studies done by Mahendra et al., and study conducted in Sri Lanka [12, 15]. However, study done by Van Dellen et al. reported knowledge of patients about their disease had no association with Asthma control (OR $=1.1 ; 95 \%$ CI 0.71-1.83) [16]. This difference might be due to socio-demographic difference between the two populations. In addition to this, the current study was done only in a single institution while study conducted by Van Dallen et al. was multicenter.

The present study illustrated, patient negative attitude was a risk factor for poorly controlled asthma. Asthma patients with negative attitude are about 5 times more likely to had poorly controlled asthma than those patients with positive attitude. This study is in line with the study conducted by Mahendra et al. and study conducted in University of Ruhuna, Sri Lanka [12, 15].

The finding of this study revealed that non-adherence to ICS was significantly associated with poorly controlled Asthma. Similarly, other studies reported that non adherence to ICS was an independent predictor of asthmarelated hospitalization $[9,17]$. In addition to this, study 
Table 2 Diseases related factors among Asthmatic patients on follow up at Jimma University Medical Center, Southwest Ethiopia, 2017

\begin{tabular}{|c|c|c|c|c|}
\hline \multirow[t]{2}{*}{ Variables } & \multicolumn{2}{|l|}{ Control } & \multicolumn{2}{|l|}{ Case } \\
\hline & Frequency & $\%$ & Frequency & $\%$ \\
\hline \multicolumn{5}{|l|}{ Severity of the disease } \\
\hline Mild & 70 & 57.9 & 5 & 4.1 \\
\hline Moderate & 42 & 37.9 & 58 & 47.9 \\
\hline Severe & 9 & 7.4 & 58 & 47.9 \\
\hline \multicolumn{5}{|l|}{ Follow up in years } \\
\hline$<5$ years & 64 & 52.9 & 33 & 27.3 \\
\hline $5-10$ years & 46 & 38.0 & 52 & 43.0 \\
\hline$>10$ years & 11 & 9.1 & 36 & 29.8 \\
\hline \multicolumn{5}{|l|}{ Comorbid conditions } \\
\hline Yes & 8 & 6.6 & 39 & 32.2 \\
\hline No & 113 & 93.4 & 82 & 67.8 \\
\hline \multicolumn{5}{|l|}{ Types of comorbid conditions } \\
\hline Depression & 1 & 12.5 & 15 & 38.5 \\
\hline Allergic rhinitis & 3 & 37.5 & 7 & 17.9 \\
\hline HTN (hypertention) & 2 & 25.0 & 16 & 41.0 \\
\hline DM (diabetic mellitus) & 1 & 12.5 & 5 & 12.8 \\
\hline Others $^{a}$ & 2 & 25.0 & 4 & 10.3 \\
\hline \multicolumn{5}{|l|}{ Precipitating diseases } \\
\hline Yes & 24 & 19.8 & 44 & 36.4 \\
\hline No & 97 & 80.2 & 77 & 63.6 \\
\hline \multicolumn{5}{|l|}{ Types of precipitating diseases } \\
\hline $\begin{array}{l}\text { GERD (gastro-esophagial reflex diseases or PUD (peptic } \\
\text { ulcer diseases) }\end{array}$ & 14 & 58.3 & 41 & 93.2 \\
\hline \multicolumn{5}{|l|}{ CAP (community acquired pneumonia) } \\
\hline Or URI (upper respiratory infection) & 25 & 33.3 & 11 & 25.3 \\
\hline UTI (urinary tract infection) & 4 & 16.7 & 2 & 4.5 \\
\hline Any pain & 1 & 4.2 & 4 & 9.1 \\
\hline \multicolumn{5}{|l|}{ Asthma exacerbation } \\
\hline Yes & 9 & 7.4 & 90 & 80.24 \\
\hline No & 112 & 92.6 & 24 & 19.8 \\
\hline \multicolumn{5}{|l|}{ Hospitalization } \\
\hline Yes & 1 & 0.8 & 15 & 12.4 \\
\hline No & 120 & 99.2 & 106 & 87.6 \\
\hline \multicolumn{5}{|l|}{ Cause of hospitalization } \\
\hline Asthma & 0 & 0.0 & 12 & 80.0 \\
\hline Others $^{\mathrm{b}}$ & 1 & 100 & 3 & 20.0 \\
\hline
\end{tabular}

a Thyroid disorder, hepatitis, retro viral infection

b Pneumonia, peptic ulcer diseases

done by Clatworthy et al. reported that low adherence to ICS was associated with poor asthma control $(\mathrm{OR}=1.35$; 95\% CI 1.18-1.55) [18]. But, our finding is inconsistent with study conducted in Netherland which reported non adherence to ICS was not associated with uncontrolled asthma $(\mathrm{OR}=0.6$; 95\% CI 0.38-1.07) [16]. This difference might be due to the fact that in the present study, poor knowledge and negative attitude about asthma was observed. This might affect drug taking behavior of the patients.

\section{Conclusion}

Poor knowledge about asthma, negative attitude about asthma, moderate and severe asthma and non-adherence to inhaled corticosteroid were independent predictors of poorly controlled asthma (Additional file 1). 
Table 3 Predictors of poorly controlled asthma among asthmatic patients in Jimma University Medical Center, Southwest Ethiopia, 2017

\begin{tabular}{|c|c|c|c|c|}
\hline Variables & $\begin{array}{l}\text { Control } N=121 \\
N(\%)\end{array}$ & $\begin{array}{l}\text { Case } \mathrm{N}=121 \\
\mathrm{~N}(\%)\end{array}$ & AOR $(95 \% \mathrm{Cl})$ & $P$ value \\
\hline \multicolumn{5}{|l|}{ Age } \\
\hline $18-34$ & $40(33.1)$ & $16(13.2)$ & 1.00 & \\
\hline $35-54$ & $52(43.0)$ & $34(28.1)$ & $0.63(0.14-2.84)$ & 0.554 \\
\hline$>55$ & $29(24.0$ & 71 (58.7) & $1.03(0.20-.5 .26)$ & 0.974 \\
\hline \multicolumn{5}{|l|}{ Residence } \\
\hline Urban & $72(59.5)$ & $42(34.7)$ & 1.00 & \\
\hline Rural & $49(40.5)$ & $79(65.3)$ & $1.25(0.94-15.23)$ & 0.1901 \\
\hline \multicolumn{5}{|l|}{ Smoking status } \\
\hline Never & $108(89.3)$ & $68(56.2)$ & 1.00 & \\
\hline Past & $9(7.4)$ & 37 (30.6) & $0.99(0.15-6.4)$ & 0.475 \\
\hline Current & $4(3.3)$ & $16(13.2)$ & $2.54(0.94-13.2)$ & 0.511 \\
\hline \multicolumn{5}{|l|}{ Asthma knowledge } \\
\hline Good & $112(92.6)$ & $35(28.9)$ & 1.00 & \\
\hline Poor & $9(7.4)$ & $86(71.1)$ & $7.30(1.72-30.85)$ & 0.007 \\
\hline \multicolumn{5}{|l|}{ Asthma attitude } \\
\hline Positive & 89 (73.6) & $53(43.8)$ & 1.00 & \\
\hline Negative & $32(26.4)$ & $68(56.2)$ & $5.10(1.40-18.7)$ & 0.014 \\
\hline \multicolumn{5}{|l|}{ Severity of asthma } \\
\hline Mild & $70(57.9)$ & $5(4.1)$ & 1.00 & \\
\hline Moderate & $42(37.9)$ & $58(47.9)$ & $13.47(2.69-47.23)$ & 0.002 \\
\hline Severe & $9(7.4)$ & $58(47.9)$ & 19.98 (7.03-78.89) & $<0.001$ \\
\hline \multicolumn{5}{|l|}{ Comorbidity } \\
\hline No & $113(93.4)$ & $82(67.8)$ & 1.00 & \\
\hline Yes & $8(6.6)$ & $39(32.2)$ & $3.27(0.71-14.9)$ & 0.126 \\
\hline \multicolumn{5}{|l|}{ ICS } \\
\hline Yes & $90(74.4)$ & $68(56.2)$ & 1.00 & \\
\hline No & $31(25.6)$ & $55(43.8)$ & $2.5(0.95-2.3)$ & 0.254 \\
\hline \multicolumn{5}{|c|}{ Level of adherence to ICS } \\
\hline Adherent & $76(84.4)$ & $13(19.1)$ & 1.00 & \\
\hline None adherent & $14(15.6)$ & $55(80.9)$ & $8.52(2.41-13.45)$ & 0.001 \\
\hline
\end{tabular}

\section{Limitation of the study}

Patient self-reporting of asthma control to either the physician or to the interviewer could intro duce misclassification bias by either categorizing cases as controls and controls as cases.

\section{Additional file}

Additional file 1. Individual anti-asthmatic and concurrent medication related factors among asthmatic patients who have follow up at Jimma University Medical Center. This data shows anti-asthmatic and concurrent medication pattern among asthmatic patients in Jimma University Medical Center.

\section{Abbreviations}

ACT: asthma control test; Cl: confidence interval; CAP: community acquired kneumonia; GERD: gastro-esophagial reflex diseases; GINA: global initiative for asthma management and prevention; ICS: inhaled corticosteroid; JUMC: Jimma University Medical Center; LABA: long acting beta, agonist; AOR: adjusted odd ratio; OR: odd ratio; PUD: peptic ulcer disease; SABA: short acting beta ${ }_{2}$ agonist; SD: standard deviation; SPSS: Statistical Package for Social Science; URI: upper respiratory infection; UTI: urinary tract infection; WHO: World Health Organization.

\section{Acknowledgements}

Authors would like to thank Jimma University for providing fund to undertake this study.

\section{Authors' contributions}

AZ (principal investigator) was made substantial contributions to conception, design of the work, methodology, analysis, data interpretation, wrote the final manuscript and managing the overall progress of the study. YM and TN had equally contributed to data analysis and interpretation of the data. KK involved in advising throughout the writing up of the paper. All authors read and approved the final manuscript. 


\section{Funding}

The study was funded by Jimma University (25000 Ethiopian birr). The funders had no role in study design, data collection, data analysis, interpretation and preparation of the manuscript

\section{Availability of data and materials}

All data generated during and/or analyzed during the study are available from the corresponding author on reasonable request.

\section{Ethics approval and consent to participate}

Ethical clearance was obtained from the Ethical Review Board of Jimma University. Patients were requested for written informed consent and confidentiality of the patients' was maintained.

\section{Consent for publication}

Not applicable.

\section{Competing interests}

The authors declare that they have no competing interests.

\section{Author details}

${ }^{1}$ Department of Pharmacy, College of Health Science, MizanTepi University, Mizan-Aman, Ethiopia. ${ }^{2}$ Department of Public Health, College of Health Sciences, MizanTepi University, Mizan-Aman, Ethiopia. ${ }^{3}$ Department of Pharmacy, Institute of Health Science, Jimma University, Jimma, Ethiopia.

Received: 7 May 2019 Accepted: 13 August 2019

Published online: 20 August 2019

\section{References}

1. Sidney S. The global burden of asthma. Chest. 2014:130:4-12

2. Masoli M, Fabian D, Holt S, Beasley R. The global burden of asthma. Allergy. 2004:59:469-78.

3. Ait-Khaled N, Enarson DA, Bissell K, Billo NE. Access to inhaled corticosteroids is key to improving quality of care for asthma in developing countries. Allergy. 2007;62:230-6.

4. Stanojevic S, Moores G, Gershon A, et al. Global asthma prevalence in adults; Findings from the cross-sectional world health survey. BMC Public Health. 2012;12:2004

5. Kirubel Z, Kifle W, Gobezie T. Assessing control of asthma in Jimma University Specialized Hospital. Ethiop J Health Sci. 2014;24(1):49-58.
6. Korinan F, Fekede BD. Uncontrolled asthma and associated factors among adult asthmatic patients. Pharmaceutical. 2016;6(11):10-25.

7. Alkhansa A, Abdelmoneim A, Abdellatif G. Evaluation of a hospital pharmacy-based pharmaceutical care services for asthma patients. Sci ELO. 2008:8(1):40-52.

8. Global Initiative for Asthma. Global strategy for asthma management and prevention. Bethesda: NIH Publication; 2013.

9. Rifaat N, Abdel-Hadya E, Hassan A. The golden factors in adherence to inhaled corticosteroids in asthma patients. Egypt J Chest Dis Tuberculosis. 2013;62:371-6

10. Keoki W, Manel P, Hugo X, Edward LP, Christine J, et al. Relationship between adherence to inhaled corticosteroids and poor outcomes among adults with asthma. J Allergy Clinlmmunol. 2004;114:1288-93.

11. Sharifi L, Pourpak Z, Heidarnazhad H, Bokaie S, Moin M. Asthma knowledge, attitude, and self-efficacy in Iranian asthmatic patients. Arch Iran Med. 2011;14(5):315-20.

12. Madhushani HPD, Subasinghe HWAS. Knowledge attitudes and practices of asthma; Does it associate with demographic factors of adult patients? Asian Pac J Health Sci. 2016;3(4):94-9.

13. Dalcin DM, Menegotto A, Zanonato L, Franciscatto F, Soliman A, Figueiredo $\mathrm{M}$, et al. Factors associated with uncontrolled asthma in Brazil. Braz J Med Biol Res. 2009;42(11):1097-103.

14. Hamdan AJ, Anwar A, Abdullah AH, Baharoon S, Halwani R, Al Shimemeri $A$, et al. Factors associated with patient visits to the emergency department for asthma therapy. BMC Pulmonary Med. 2012;12(80):1471-2466.

15. Mahendra K, Jose J, Naveen MR, Kumarswamy M. Assessing the knowledge, attitude and medication adherence among asthma patients in a rural population. Asian J Pharm Clin Res. 2011;4:193-7.

16. Van Dellen Q, Stronks K, Bindels P, Ory F, Bruil J, Aldren W. Predictors of Asthma control in children from different ethnic origin living in Amsterdam. Respir Med. 2007;101:779-85.

17. Keoki W, Manel P, Hugo X, Edward LP, Christine J, et al. Relationship between adherence to inhaled corticosteroids and poor outcomes among adults with asthma. J Allergy Clin Immunol. 2004;114:12-23.

18. Clatworthy J, Price D, Ryan D, Haughney J, Horne R. The value of selfreport assessment of adherence, rhinitis and smoking in relation to asthma control. Prim Care Respir J. 2009;18:300-5.

\section{Publisher's Note}

Springer Nature remains neutral with regard to jurisdictional claims in published maps and institutional affiliations.
Ready to submit your research? Choose BMC and benefit from

- fast, convenient online submission

- thorough peer review by experienced researchers in your field

- rapid publication on acceptance

- support for research data, including large and complex data types

- gold Open Access which fosters wider collaboration and increased citations

- maximum visibility for your research: over 100M website views per year

At BMC, research is always in progress.

Learn more biomedcentral.com/submissions 